\title{
Recommendations for the conduct of economic evaluations in osteoporosis: outcomes of an experts' consensus meeting organized by the European Society for Clinical and Economic Aspects of Osteoporosis, Osteoarthritis and Musculoskeletal Diseases (ESCEO) and the US branch of the International Osteoporosis Foundation
}

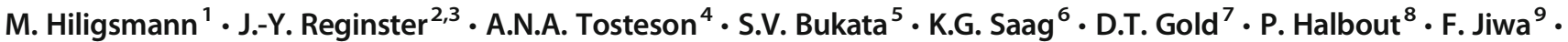

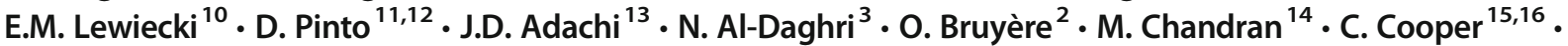 \\ N.C. Harvey ${ }^{15}$ - T.A. Einhorn ${ }^{17}$ • J.A. Kanis ${ }^{18,19,20}$ - D.L. Kendler ${ }^{21} \cdot$ O.D. Messina ${ }^{22} \cdot$ R. Rizzoli $^{23} \cdot$ L. Si $^{24,25}$ • \\ S. Silverman 26
}

Received: 23 August 2018 / Accepted: 16 October 2018 / Published online: 31 October 2018

(C) The Author(s) 2018

\begin{abstract}
Summary Economic evaluations are increasingly used to assess the value of health interventions, but variable quality and heterogeneity limit the use of these evaluations by decision-makers. These recommendations provide guidance for the design, conduct, and reporting of economic evaluations in osteoporosis to improve their transparency, comparability, and methodologic standards.

Introduction This paper aims to provide recommendations for the conduct of economic evaluations in osteoporosis in order to improve their transparency, comparability, and methodologic standards.

Methods A working group was convened by the European Society for Clinical and Economic Aspects of Osteoporosis and Osteoarthritis to make recommendations for the design, conduct, and reporting of economic evaluations in osteoporosis, to define an osteoporosis-specific reference case to serve a minimum standard for all economic analyses in osteoporosis, to discuss methodologic challenges and initiate a call for research. A literature review, a face-to-face meeting in New York City (including 11 experts), and a review/approval by a larger group of experts worldwide (including 23 experts in total) were conducted.

Results Recommendations on the type of economic evaluation, methods for economic evaluation, modeling aspects, base-case analysis and population, excess mortality, fracture costs and disutility, treatment characteristics, and model validation were provided. Recommendations for reporting economic evaluations in osteoporosis were also made and an osteoporosis-specific checklist was designed that includes items to report when performing an economic evaluation in osteoporosis. Further, 12 minimum criteria for economic evaluations in osteoporosis were identified and 12 methodologic challenges and need for further research were discussed.

Conclusion While the working group acknowledges challenges and the need for further research, these recommendations are intended to supplement general and national guidelines for economic evaluations, improve transparency, quality, and comparability of economic evaluations in osteoporosis, and maintain methodologic standards to increase their use by decision-makers.
\end{abstract}

Keywords Cost-effectiveness $\cdot$ Economic evaluation $\cdot$ Osteoporosis $\cdot$ Recommendations $\cdot$ Reference case

A paper endorsed by the Scientific Advisory Board of ESCEO, the Committee of Scientific Advisors and the Committee of National Societies of IOF, the US National Osteoporosis Foundation and Osteoporosis Canada

M. Hiligsmann

m.hiligsmann@maastrichtuniversity.nl

Extended author information available on the last page of the article

\section{Introduction}

Considering the limited healthcare resources available around the world, as well as recent major innovations in the management of osteoporosis, it has become increasingly important for decision-makers to allocate healthcare resources efficiently [1]. Economic evaluations that compare interventions in terms of costs and outcomes are increasingly used by decision- 
makers to assess the value of healthcare interventions. In particular, economic evaluations now play an important role in pricing and reimbursement decisions [2].

In the field of osteoporosis, the number of economic evaluations has increased markedly in recent years $[3,4]$. Economic evaluations have been conducted to assess the cost-effectiveness of anti-osteoporotic drugs $[3,5,6]$, to identify cost-effective intervention thresholds for fracture risk [7-9], and to estimate the cost-effectiveness of osteoporosis programs for screening patients $[10,11]$ or fracture liaison services for secondary fracture prevention [12]. Previous economic analyses have suggested that anti-osteoporotic drugs are generally cost-effective for the treatment of postmenopausal women over the age 60-65 years with low bone mass or an additional risk factor such as the presence of a previous fracture and they are generally cost-saving over the age of 80 years [3]. It is difficult, however, to make clear comparisons of cost-effectiveness of interventions due to differences of study designs, heterogeneity in model structure, assumptions, fracture risk, comparators, and the individual country setting [3]. In addition, the variable quality and reporting of these economic evaluations limit their comparability and use by decision-makers [3].

A number of general and national guidelines and recommendations for the design, conduct, and reporting of costeffectiveness analyses have been produced, including the series of Modelling Good Research Practices published by the International Society for Pharmacoeconomics and Outcomes Research (ISPOR) [13], the Consolidated Health Economic Evaluation Reporting Standards (CHEERS) checklist for good reporting of economic evaluation [14], and the recommendations for Conduct, Methodological Practices, and Reporting of Cost-effectiveness Analyses from the Second Panel on Cost-Effectiveness in Health and Medicine [15]. An important limitation of such methodological standards is that they are, of necessity, fairly general and tend to neglect the unique circumstances that surround particular clinical context [16]. A few disease-specific guidelines have thus been developed to provide additional disease-specific recommendations for economic evaluations [16-20], including one that is outdated in the field of osteoporosis [19]. To supplement the generally accepted methodologic standards, disease-specific recommendations for the conduct and reporting of economic evaluations can be very useful for improving the quality and use of economic evaluations.

In recent years, the management of osteoporosis and supportive data has evolved [1]. Incorporating emerging evidence about osteoporosis and osteoporosis treatment in a new economic guideline is therefore important. Recent evidence includes the development of new osteoporosis treatments (e.g., abaloparatide [21] and romosozumab [22]), the value of sequential therapy [23, 24], effect after treatment discontinuation [25], new data about imminent risk after fractures [26], and the worldwide increase in the use of fracture risk algorithm such as FRAX® [27].

The aim of this paper is to provide recommendations for the conduct of economic evaluations in osteoporosis. These recommendations, which supplement general and national guidelines, can guide researchers in designing appropriate and high-quality economic evaluations and help decision-makers and reviewers to assess the quality of these studies. Our study further aims to improve transparency and comparability and maintain methodologic standards of these studies.

More specifically, this study has four objectives: (1) to make recommendations for the design and conduct of economic evaluations in osteoporosis; (2) to make recommendations regarding the reporting of economic evaluations in osteoporosis, as a complement to the CHEERS checklist [14]; (3) to define an osteoporosis-specific reference case to serve a minimum standard for all economic analyses in osteoporosis to reduce inter-study heterogeneity facilitating inter-study comparisons; and (4) to discuss methodologic challenges and directions for research for economic evaluation in osteoporosis to improve the quality of future studies.

\section{Methods}

An international working group was formed to develop recommendations for the conduct of economic evaluations in the field of osteoporosis. The working group consisted of clinical scientists and health economic experts in the field of osteoporosis who were selected by the Scientific Advisory Board of European Society on Clinical and Economic Aspects of Osteoporosis, Osteoarthritis and Musculoskeletal Diseases (ESCEO). A three-step process was followed.

First, in preparation for a working group meeting, $\mathrm{MH}$ and SS conducted a literature review to identify a list of relevant articles to share with the working group. The literature search was conducted in January 2018 using the key terms "economic evaluation or cost-effectiveness" and "osteoporosis" in PubMed. The list of relevant articles $(n=17)$ included a background study on health technology assessment and economic evaluation [1]; reviews of economic evaluation in osteoporosis [3, 28]; some examples of published economic evaluations in osteoporosis $[5,8,29-31]$; the technical appendix of a publication [32]; a report of the Institute for Clinical and Economic Review in the USA [33]; a report of the National Institute for Clinical Excellence and Health in the UK [34]; the CHEERS checklist for good reporting of economic evaluation [14]; the recommendations for Conduct, Methodological Practices, and Reporting of Cost-effectiveness Analyses from the Second Panel on Cost-Effectiveness in Health and Medicine [15]; and some disease-specific guidelines for economic evaluations [16-19]. A preliminary list of areas where 
recommendations would be needed was developed by $\mathrm{MH}$ and reviewed/completed by SS and JYR.

Second, a 1-day in-person meeting was conducted on February 12, 2018, in New York City (NYC) to define and discuss the recommendations. Specialists in rheumatology, endocrinology, physical medicine and rehabilitation, geriatrics, physiotherapy, epidemiology, and health economics, as well as patient representatives $(n=11)$ were invited to participate. The meeting started with four short presentations about emerging evidence about osteoporosis treatment options (by KGS), modeling the cost-effectiveness of an osteoporotic treatment (by $\mathrm{MH}$ ), overview and challenges of cost-effectiveness of osteoporosis medications (by SS), and existing guidelines for the conduct of economic evaluations (by ANAT). A group discussion led by $\mathrm{MH}$ and SS was then conducted to define recommendations for the conduct of economic evaluations and to answer all the study's objectives. Each participant had the opportunity to comment on the areas for recommendations and to add additional ones. Following the meeting, members of the writing group (MH, JYR, SS, ANAT, and SVB) drafted the recommendations for the conduct of economic evaluations and a first report on the meeting consensus; this was reviewed and commented on by all participants from the NYC meeting.

As a third step, the recommendations for the conduct of economic evaluations was sent to a larger group of clinical and economic experts from around the world $(n=23)$ to review, comment on, and validate the recommendations.

The present recommendations were developed independently by the authors, with funding sources having no role in the writing or editing of this document. In addition, each member of the working group agreed to declare their potential conflict of interest, if any, in the process of article submission.

\section{Results}

First, it is strongly recommended that the methodological choice, data, and assumptions used in an economic evaluation be clearly explained, justified, and referenced. It is further recommended that data inputs and main assumptions should be summarized in tables in the main article or in appendices. It is important that authors of an economic evaluation provide enough information in a manuscript to allow another researcher to fully understand it and potentially replicate it. It is also recommended to use national/ local input data as much as possible and to be in line with the country-specific osteoporotic fracture clinical management algorithm.

\section{Recommendations for the design and conduct of economic evaluations in osteoporosis}

The recommendations for the design and conduct of an economic evaluation in osteoporosis are outlined in Table 1 and further details are discussed below.

\section{Type of economic evaluation}

An economic evaluation compares at least two health interventions in terms of costs and effectiveness outcomes. The most frequently used methods are cost-utility analysis (using quality-adjusted life years (QALY) as the outcome) and costeffectiveness analysis that expresses outcomes in natural units such as life years or fracture events [1]. The QALY estimator is an attractive outcome measure in the field of osteoporosis

Table 1 Recommendations for the design and conduct of an economic evaluation in osteoporosis

Type of economic evaluation

- Cost-utility analysis using QALY as outcome

Method for the conduct of economic evaluation

- A model-based economic evaluation

Modeling technique

- Lifetime horizon

- Markov model is appropriate (6 months/1 year cycle length)

- Avoid hierarchy of fractures and restrictions after fracture events

- Hip, clinical vertebral, and non-vertebral non-hip fracture

Base-case analysis and population

- Multiple scenarios: age range, BMD, and fracture risk scenarios

- At least a scenario including a 10-year risk of a major osteoporotic fracture equal to $20 \%$ or with a BMD T-score $\leq-2.5$ with or without fractures

- The FRAX® or GARVAN® tools can be used to model fracture risk

- Increased risk after fracture events within the model

Mortality

- Excess mortality after hip fractures

- Proportion attribute to the fracture (e.g., 25-30\%)

Fracture costs and utility

- Societal and/or healthcare payer perspective

- Acute fracture costs

- Long-term costs after hip fracture (attributable to the fracture)

- First year and subsequent years' effects of fractures on disutility

- National ICUROS data if available

- An additional effect (on costs and/or utility) after multiple fractures

Treatment characteristics

- Treatment duration similar to guidelines or RCTs

- Comparators: no treatment and relevant active osteoporotic agent(s)

- Sequential therapy may be considered as intervention/comparators

- Efficacy data from RCTs, (network) meta-analysis

- In the absence of hip/wrist specific efficacy data, use of non-vertebral or clinical fracture efficacy data

- Treatment effects after discontinuation depending on treatment

- Medication adherence as sensitivity analysis

- Drug costs and administration/monitoring costs

- Adverse events 
because it offers the advantage of simultaneously capturing the morbidity and mortality effects of fracture events and thus of anti-osteoporosis treatment [28]. The use of the QALY was further endorsed by the 2011 OMERACT economics working group for economic studies in musculoskeletal diseases [35] and is the common metric used by several national health technology assessment agencies. There are however some limitations of QALY namely ethical considerations, methodological considerations and theoretical assumptions, and condition specific considerations [36]. Despite these limitations and given the lack of robust alternatives, the QALY is still regarded as the most rigorous methodological tool available and it is recommended that QALY be used as the effectiveness outcome when conducting an economic evaluation in osteoporosis. Presenting disaggregated outcomes such as life years and fracture events is further recommended (see the "Recommendations regarding the reporting of economic evaluations in osteoporosis" section) but does not replace the need for a QALY analysis.

\section{Method for the conduct of economic evaluation}

Economic evaluation can be performed alongside randomized controlled trials (RCTs), called trial-based economic evaluation, or separately using decision-analytic modeling [1]. A trial-based economic evaluation presents, however, some major weaknesses that reduce its usefulness in informing decision-makers about the economic value of antiosteoporosis interventions. These include a failure to compare all relevant options and a truncated time horizon [37], as well as the limited generalizability of persons who participate in clinical trials, and finally, this approach does not capture the long-term benefits of preventing fractures or long-term sequelae of the intervention(s).

A model-based economic evaluation that uses mathematical techniques to summarize available information about a disease and its implications is recommended, especially as the prevention of an osteoporotic fracture, in particular of the hip or vertebra, has long-term consequences on costs and outcomes that may not be captured by trial data. Modeling is indeed useful to extrapolate beyond clinical trials, to combine multiple sources of evidence (e.g., RCTs, epidemiological, clinical, and economic data) and therefore to answer more relevant policy questions [38]. A trial-based economic evaluation could be conducted alongside RCTs but should be complemented with a model to address the long-term effects of the osteoporosis treatment.

\section{Modeling technique}

A model-based economic evaluation with a lifetime horizon is recommended to capture the long-term consequences of interventions in terms of costs and outcomes. The choice and development of the model should follow the ISPOR/SMDM guidelines on modeling [13]. A Markov modeling technique has commonly been used in the field of osteoporosis [3] and is appropriate because osteoporosis is a chronic disease characterized by a recurrence of events that can be reflected in Markov health states and fracture risk is continuous (but changing) over time. The choice of cycle length (e.g., 6 months or 1 year) should be clearly motivated depending on treatment duration/ adherence and availability of data. It is recommended to use models that simulate fracture events where a relative risk reduction for therapy is applied to baseline age-specific fracture incidence rates in the population of interest.

It is optimal to avoid a hierarchy of fractures and restrictions after fracture events (such as the absence of non-hip fracture after a previous hip fracture or a limit to the number of fracture events), as real-world patients may experience any number and type of fractures. This could be done with the use of a Markov microsimulation model [29], discrete-event simulation, or by enlarging the number of health states in a Markov cohort model. To adequately accomplish this, more data on the effects of multiple fractures on costs and QALY would be interesting.

It is further recommended that hip, clinical vertebral, and non-vertebral non-hip fractures (that are associated with osteoporosis [39]) be included. Non-vertebral non-hip fractures could include wrist fracture and/or other osteoporotic fractures. Although some (minor) effects of morphometric vertebral fractures on utilities and an increased risk of future fractures are recognized, it is recommended at this stage to include only clinical osteoporotic vertebral fractures.

\section{Base-case analysis/population}

It is recommended to analyze multiple scenarios that include age range (e.g., 50 to 80 years) and fracture risk levels (e.g., 10year risk of a major osteoporotic fracture equal to $10 \%, 20 \%$, and $30 \%$, or with BMD T-score $=$ or $\leq-2.5$ with and without previous fractures). Base-case population could be based on reimbursement criteria currently in place or on guidelines like those of the American Association of Clinical Endocrinologists (AACE) which define high risk in the USA [40].

It is acknowledged that defining a single-reference case scenario is difficult since the definition of high-risk patients and local reimbursement criteria differs between countries. It is however recommended that at least one scenario including a 10 -year risk of a major osteoporotic fracture equal to $20 \%$ or a population with a BMD T-score $\leq-2.5$ at one or two age cohorts (such as 65 and/or 70 years) be conducted. It is recommended to conduct more than one of these scenarios and to include a large age spectrum (e.g., 50-80 years).

To adequately represent the fracture risk of the population of interest, fracture risk from the general population needs to be adjusted according to BMD level [41] or the presence of fracture risk factor such as previous fractures. FRAX ${ }^{\circledR}$ or the 
GARVAN® tools that estimate a 5- and/or 10-year probability/ incidence of fractures can be used to model fracture risk and to assess the effect of different population risks.

It is further recommended, during design of the model, to incorporate an increased risk after new fracture events, in line with studies suggesting an increased fracture risk after fracture $[26,42]$.

\section{Mortality}

Modeling national probabilities of death and to apply a relative risk increase due to fracture events are recommended. An excess mortality after hip fractures and clinical vertebral fractures should be modeled, as this has been widely demonstrated $[43,44]$. An excess mortality after non-hip non-vertebral fractures could be modeled once further data will become available. A scenario including only an excess mortality after hip fractures should be included (see the "Recommendations regarding the reporting of economic evaluations in osteoporosis " section). Taking into account that only a proportion of excess mortality observed in previous studies could be attributable to the fracture event is further recommended. Levels of $25 \%-$ $30 \%[44,45]$ have frequently been associated with hip fracture based on published studies.

\section{Fracture costs and utilities}

Resource use and cost data should be derived from the national/ local setting for the analysis. A societal and/or a payer perspective according to local HTA guideline are recommended for the cost assessment. The societal perspective includes healthcare, patient and family costs and productivity losses. Acute costs of managing a fracture need to be included for all fractures. Hip fractures are also associated with increased admission to longterm care facilities. This needs to be included for example by incorporating the probability of admissions to nursing home following hip fractures. For the long-term cost of nursing homes, it is important to include only costs attributable to the fracture. In the absence of sufficient data, it is recommended to not include long-term costs for non-hip fractures.

For utility values, using the age-specific population norms and applying the disutility multipliers following fractures by fracture site (first year and subsequent years) are recommended [46]. National ICUROS data are recommended if available. Overall ICUROS [47, 48] could be used in the absence of national data for utility. For the collection of new utility data, the EQ-5D-5L questionnaire is recommended [49] using a relevant national valuation set. Data from ICUROS may allow adjusting baseline, while data from neighboring countries with similar characteristics could be considered if national data are not available. An additional effect (on costs and/or utility) after multiple fractures could also be modeled although further data would be needed.

\section{Treatment characteristics}

Modeling an anti-osteoporotic treatment for duration of time similar to RCTs, indications, or guidelines (e.g., 3 or 5 years for antiresorptive, 12-24 months for anabolics) is recommended. If sequential data are available, longer treatment may be considered with an anabolic followed by antiresorptive.

The list of comparators should include "no treatment" (still the current standard of care in most cases especially for primary prevention) and active comparators that are relevant for decision-makers. The purpose of the comparison should be clearly stated. With emerging evidence about the value of sequential therapy $[24,50,51]$, sequential therapy could also be included in intervention/comparators. Comparators to sequential therapy could include monotherapy or other anabolicantiresorptive combinations.

Efficacy data from treatment should be derived from RCT or meta-analysis, and be fracture site specific. Network metaanalysis should also be used for indirect comparisons between drugs. Confidence intervals need to be included and used in the model in the probabilistic sensitivity analyses. Some antiosteoporotic agents do not have efficacy data at the hip or wrist. It is recommended to use the reduction in nonvertebral or clinical fracture rate with treatment as a surrogate for reduction in hip fracture rate in the base case. This assumption should be tested in sensitivity analyses and observational studies or systematic reviews of multiple RCTs (with preference for using pooled individual level analysis) would be interesting to confirm it.

Effects of treatment discontinuation need to be modeled and can be different between drug options and be supported by the evidence that is available for the drug options being evaluated. For oral bisphosphonates, a linear decrease in treatment effectiveness for a duration similar to treatment duration is commonly assumed [3] based on studies assessing bone loss after discontinuation [52] and fracture data [53]. A longer effect for anabolic agents should be assumed [54, 55] and a limited effect after discontinuation of denosumab should be included in line with recent studies suggesting rapid bone loss and increased risk of multiple vertebral fractures [56].

It is recommended that all therapy costs be included. Drug costs need to be derived from official drug prices listing in the country in which the study is being conducted. In the USA, there is substantial variability in prices and the average wholesale price (AWP) could be recommended. In addition to drug cost, administration costs need to be included, such as regular visits to general practitioner (e.g., one per 6 months in line with previous economic evaluations), BMD measurement (e.g., once per 2 years), and injection/infusion cost.

The use of real-world medication adherence in an alternative scenario is recommended, as well as sensitivity analyses varying adherence levels. Adherence to anti-osteoporosis medications could be poor in real life and affect clinical and 
economic outcomes [57]. Approaches and examples to incorporate medication adherence in economic evaluations in osteoporosis have been published [58-60].

Finally, important side effects or extra-skeletal benefits of treatments that have an impact on costs and/or utility need to be included. This is especially true for drugs like raloxifene that also reduces the risk of breast cancer.

\section{Model validation}

The model needs to be validated in line with the ISPOR/ SMDM guidelines for model transparency and validation including face validity, internal validity, cross validity external validity, and predictive validity [61]. Especially, it is important that the model replicates all population estimates for each individual parameter [19]. Validation process should be described and reported (e.g., by estimating the number of fractures produced by the model, lifetime risk of fracture, or life expectancy and comparing them to (epidemiological) data).

\section{Recommendations regarding the reporting of economic evaluations in osteoporosis}

It is recommended to use the CHEERS checklist for reporting the economic evaluation (and include it as an appendix of the paper). The CHEERS proposes a checklist of 24 items, each with a corresponding recommendation. This checklist has achieved widespread recognition and acceptance in health economics [14].

For the presentation of results and sensitivity analyses, recommendations are as follows:

- Present disaggregated outcomes (such as fracture events, life years, therapy/drug costs, other healthcare costs) for the intervention and comparator(s)

- Present incremental costs and outcomes between intervention and comparator(s)

- Report incremental cost-effectiveness ratio (in terms of costs per QALY gained)

- Characterize uncertainty and heterogeneity by the conduct of:

- Single-case scenario (defined previously)

- Multiple scenarios (age segment; fracture risk)

- One-way sensitivity analyses presented in tables or tornado diagrams

- Probabilistic sensitivity analyses presented in costeffectiveness acceptability curves.

Several one-way sensitivity analyses should be conducted on fracture costs (e.g., long-term cost), excess mortality after fractures, effect of fracture on utility, discount rates and on-treatment characteristics such as the treatment effect (e.g., if non-vertebral was used for hip), medication adherence, effect of treatment after discontinuation, treatment costs, and side effects.

For probabilistic sensitivity analyses, using distributions for as many parameters with stochastic uncertainty as possible is recommended (following guidelines for economic evaluation [62]). It is especially important to model the treatment effects with a distribution (e.g., a log-normal distribution).

In addition to the CHEERS checklist, it is recommended for authors to report on and justify nine osteoporotic-specific reporting criteria (see Table 2). This includes the reporting and justification of key modeling aspects (choice of model, transition probabilities, effect of fracture on costs, mortality, and utility) and key treatment characteristics including the effect of treatment per fracture site, the effect of treatment after discontinuation, the inclusion and approach used to model medication adherence, therapy costs, and side effects.

\section{Osteoporosis-specific reference case}

A set of criteria with which all economic evaluations in osteoporosis, at minimum, should comply was also developed. Minimum requirements will increase the comparability and assessment of studies as well as maintain minimum standards. The set of minimum criteria is based on the recommendations and refers to the methods which are of importance in the view of the working group. It may be necessary to deviate from this set of minimum criteria, but the reasons and nature of deviations should be well substantiated and clearly described. The list of minimum criteria is presented in Table 3, which is explained here below.

Despite the aforementioned limitations of QALY and given the lack of robust alternatives, the QALY is still regarded as the most rigorous methodological tool available for economic evaluation (criterion 1) and allows the incorporation of the effects of fractures on both mortality and morbidity. To capture the long-term consequences of preventing fractures and thus fully capture the costs and outcomes of anti-osteoporotic treatment, a modeling technique is deemed appropriate (criterion 2) and should have a long-term (ideally a lifetime) time horizon (criterion 3). The model should at minimum include hip and clinical vertebral fractures (criterion 5) and be conducted from at least a payer and/or healthcare perspective (criterion 4) and in line with national guidelines. A payer perspective could require a shorter than lifetime time horizon. Excess mortality after hip and clinical vertebral fractures should be included (criterion 6), as well as short-term and long-term effects of fracture on utility (criterion 7) and longterm costs of hip fracture (criterion 8). Treatment characteristics should include effect on fractures during treatment and after discontinuation, medication adherence, side effects, and treatment costs (criterion 9). It is further recommended to conduct multiple scenarios (criterion 10), to present disaggregated 
Table 2 Osteoporosis-specific checklist-specific items to include when reporting economic evaluations on osteoporosis*

\begin{tabular}{|c|c|c|c|}
\hline Item & $\begin{array}{l}\text { Item } \\
\text { no. }\end{array}$ & Recommendation & $\begin{array}{l}\text { Reported on page no./ } \\
\text { line no. }\end{array}$ \\
\hline Transition probabilities & 1 & $\begin{array}{l}\text { Report the transition probabilities and how } \\
\text { they were estimated (including increased } \\
\text { fracture risk) }\end{array}$ & \\
\hline $\begin{array}{l}\text { Excess mortality } \\
\text { after fractures }\end{array}$ & 2 & $\begin{array}{l}\text { Describe approaches and data sources used for } \\
\text { the excess mortality after fractures }\end{array}$ & \\
\hline Fractures costs & 3 & $\begin{array}{l}\text { Describe approaches and data sources used for } \\
\text { fractures costs }\end{array}$ & \\
\hline $\begin{array}{l}\text { Fractures effects } \\
\text { on utility }\end{array}$ & 4 & $\begin{array}{l}\text { Describe approaches and data sources used for } \\
\text { the effects of fractures on utility }\end{array}$ & \\
\hline $\begin{array}{l}\text { Treatment effect } \\
\text { during treatment }\end{array}$ & 5 & $\begin{array}{l}\text { Describe fully the methods used for the } \\
\text { identification, selection, and synthesis of } \\
\text { clinical effectiveness data (per fracture site) }\end{array}$ & \\
\hline $\begin{array}{l}\text { Treatment effect after } \\
\text { discontinuation }\end{array}$ & 6 & $\begin{array}{l}\text { Describe fully the methods used for the } \\
\text { treatment effect after discontinuation }\end{array}$ & \\
\hline Medication adherence & 7 & $\begin{array}{l}\text { Describe approaches and data sources used for } \\
\text { modeling medication adherence }\end{array}$ & \\
\hline Treatment costs & 8 & $\begin{array}{l}\text { Describe approaches and data sources used } \\
\text { for therapy costs }\end{array}$ & \\
\hline Treatment side effects & 9 & $\begin{array}{l}\text { Describe approaches and data sources used for } \\
\text { costs and utilities effects of adverse events }\end{array}$ & \\
\hline
\end{tabular}

*In addition to the CHEERS checklist [14] outcomes, incremental costs and outcomes for each intervention and ICER (criterion 11) and to conduct one-way and probabilistic sensitivity analyses (criterion 12).

\section{Some methodologic challenges and call for research of economic evaluations in osteoporosis}

Several (methodologic) challenges and areas where further research is needed were identified and are organized according to probabilities, mortality, costs and utilities, treatments characteristics, and others.

Table 3 A set of minimum criteria for an economic evaluation in osteoporosis

1) Cost-utility analysis with QALY as outcome

2) Modeling technique (with limited restrictions)

3) Long-term (lifetime) horizon

4) Payer and/or societal perspective

5) At minimum hip and clinical vertebral fracture

6) Excess mortality after hip and clinical vertebral fractures

7) Short-term/long-term effects of fracture on utility

8) Long-term costs of hip fracture

9) Treatment characteristics*: effect on fractures during treatment and after discontinuation; medication adherence; side effects; therapy costs

10) Multiple scenarios (age, fracture risk, BMD)

11) Presentation of disaggregated outcomes, incremental costs, and outcomes for each intervention and incremental cost-effectiveness ratios

12) One-way and probabilistic sensitivity analyses

*Medication adherence and side effects could be included in sensitivity analyses

\section{Modeling fracture risk after a predefined 10-year risk of fractures}

The use of a 10-year probability of fracture (e.g., $10 \%$ or $20 \%$ risk of major fractures in the next 10 years) has increasingly been used in economic evaluations in osteoporosis [63]. There are some data on long-term risk of fractures [64, 65], but cannot account for secular trends in fracture risk or mortality during or after the 10-year period. It can be conservatively assumed that the age- and sex-specific fracture risk remains stable or assume changes to reflect historical differences in the age-specific fracture incidence.

\section{Increased risk of fractures after fracture and over time}

There is emerging evidence that fracture risk increases after a fracture, and that this increase depends on fracture site and decreases over time, while not returning to baseline risk [26]. Not all economic analyses have included an increased risk when a new fracture occurred in the model, and they have often constrained the increase risk to a specific fracture site. Further data would be needed to know the effects of several fractures (from the same and different sites) on fracture risk, and modeling should better reflect this effect.

\section{Excess mortality after non-hip non-vertebral fractures}

The working group recognizes the excess mortality after hip fractures; however, a consensus was difficult to obtain for clinical vertebral fractures. Most experts suggested that there 
is an excess mortality after clinical vertebral (similar to the effects of hip fracture), while others suggested the need for additional data before modeling excess mortality after clinical vertebral fractures. Conducting both scenarios is recommended (with and without excess mortality after clinical vertebral fracture) and additional data on the effects of clinical vertebral fractures on mortality would be needed. More studies on the duration of the excess mortality attributable to the fracture event would also be needed. Recently, a study also suggested a mortality effect after non-hip non-vertebral fractures [66] and more studies would be interesting to confirm this. Further work would also be needed to address the excess mortality after a fracture that can be directly attributable to the fracture event.

\section{Long-term cost/care after hip fractures}

It is recommended to include the long-term cost/care attributable to hip fractures. However, before that can be done, a better understanding of the long-term cost/care and the attribution of fracture to admission to nursing homes is needed. Further research addressing fractureattributable length of stay in long-term care is also needed along with research investigating long-term costs following clinical vertebral fractures that is expected to differ widely between geographic regions/countries.

\section{Conceptualization of the societal perspective}

The working group acknowledged great variety in the conceptualization and interpretation of the societal perspective in economic evaluations of osteoporosis interventions [67]. We further need additional research on what social factors lead to indirect costs in the societal realm and to assess informal care in osteoporosis. How we measure caregiver burden and community burden will be especially important. Given that societal factors differ widely between societies, more data are needed to investigate and then specify the country-specific societal costs of fractures.

\section{Modeling multiple fractures and their severity}

It is optimal incorporating multiple fractures within the model and avoiding hierarchy of fractures and restrictions after fracture events. Further studies would be needed to investigate the cost and utility effects of multiple fractures as well as to assess the consequences of fracture severity, especially for vertebral fractures. Most previous economic analyses did not include fracture number or severity within the model.

\section{Appropriate comparators}

Identifying the appropriate comparator for an economic analysis in osteoporosis is rarely straightforward. Comparators could be based on treatment guidelines or payer reimbursement. Indirect comparisons are especially uncertain because of the differences in baseline fracture risk between RCTs.

\section{Absence of hip fracture data}

Some RCTs are not powered to detect significant differences in hip fractures due to a small number of events. This guidance recommends utilizing the reduction in non-vertebral (or clinical) fracture rate with treatment as a surrogate for reduction in hip fracture rate in base case. This assumption should be confirmed using observational studies or systematic reviews of multiple RCTs (with preference for using individual data with propensity scoring).

\section{Persistence of treatment effects after discontinuation}

There is a need to better understand the anti-fracture effects of anti-osteoporosis treatment after discontinuation for most drug treatment. Longer-term fracture outcome studies after treatment discontinuation, especially in real-world settings would be needed. The treatment effects after stopping a sequential therapy also require investigation. In the meantime, sensitivity analyses need to be conducted on offset time.

\section{Variation in response based on treatment history}

It is needed to better understand the treatment response based on treatment history for both mono and sequential therapy. Some studies have suggested that treatment response may be impacted by previous treatment [24].

\section{Treatment side effects}

Further research needs to be conducted to adequately incorporate medication side effects in economic models. More specifically, research is needed on how we might capture cost for atypical fractures or multiple vertebral fractures, and the disutility associated with such events.

\section{Insufficient data in male}

The working group acknowledged current insufficient fracture data for male. Further studies would thus be needed to investigate the efficacy of anti-osteoporotic drugs in male. 


\section{Cost-effectiveness in subpopulations}

There is a further need to better understand the costeffectiveness of anti-osteoporotic agents in subpopulations of patients at higher risk such as those with diabetes, rheumatoid arthritis, or glucocorticoid users. Efficacy data on all drug classes in these specific populations are also needed.

\section{Discussion}

This study provides recommendations for the design, conduct, and reporting of economic evaluations of osteoporosis interventions in order to improve transparency, comparability, and to maintain methodologic standards. This could finally contribute to a more efficient allocation of resources devoted to osteoporosis management.

These recommendations should be seen as supplemental to general and national guidelines for economic evaluations. Disease-specific recommendations for economic evaluations are important in order to characterize unique circumstances that surround particular clinical contexts. As an illustration, the CHEERS checklist for reporting the economic evaluation, which has achieved widespread recognition and acceptance in health economics, is recommended [14]. But given that CHEERS is, of necessity, fairly general, a nine-item osteoporosis-specific checklist for reporting economic evaluation that may be more effective for osteoporosis was designed to complement CHEERS.

This project further aimed to identify a minimum set of criteria that an economic evaluation in osteoporosis should have. Such a set of criteria could help reduce inter-study heterogeneity as well as define minimum standards. This list should be considered only as a minimum set of criteria.

Our recommendations are intended for any researchers interested in conducting an economic evaluation in the field of osteoporosis and also to help decision-makers, reviewers, and editors to assess the quality of these studies. It is recommended that researchers check the set of minimum criteria and include the osteoporosis-specific checklist for reporting in addition to CHEERS in appendices of scientific journals. If the osteoporosis health economics community follows these recommendations, this would improve the transparency, quality, and comparability of economic evaluations of osteoporosis interventions and this may facilitate and increase its use by decision-makers. We acknowledge that it may be necessary to deviate from these recommendations in some circumstances, but the reasons and nature of deviations must be well substantiated and clearly described by the authors.

There are limitations to these recommendations that deserve mention. First, although a large group of experts worldwide was included and combined with a literature review, a face-to-face meeting, a small writing team, an additional and an additional experts review, a more formal group process such as a Delphi panel could have led to some differences in recommendations. Second, although these recommendations could be applied to any type of osteoporosis intervention, the guidance focused mainly on costeffectiveness analyses of drug treatment rather than on nonpharmacological interventions. Third, recommendations were not possible for all aspects of model-based economic evaluations in osteoporosis as several methodological challenges of economic evaluations requiring further research were identified. In addition, no recommendation on thresholds to define an intervention cost-effective was provided, as this question is out of the scope of this study and depends on national recommendations. Finally, evaluating the effect of implementation of these recommendations on the quality of future economic evaluations in osteoporosis should be considered. Although some disease-specific recommendations for economic evaluations have been developed [16-19], this study is one of the first that provides a list of recommendations and minimum requirements for the design, conduct, and reporting of an osteoporosis-specific economic evaluation.

In conclusion, these recommendations are provided as a supplement to general and national guidelines for economic evaluations and are intended to improve the transparency, quality, and comparability of economic evaluations in osteoporosis. Promoting high-quality methodology standards has the potential to increase their use by decision-makers and to lead to a more effective allocation of resources.

Acknowledgments This meeting was entirely funded by ESCEO which received an Unrestricted Educational Grant from IOF USA. IOF USA was partially funded through an Unrestricted Educational Grant from Radius Health. IOF USA and Radius Health were not involved in the selection of the participants, choice of the venue, and preparation of the program and were not consulted regarding the outcomes of the meeting, the content of the manuscript, or the selection of the Journal to which the manuscript was submitted. All these choices were made by the Scientific Advisory Board of ESCEO and by the authors of the manuscript without any external influence. The authors extend their appreciation to the Chair for Biomarkers of Chronic Diseases, King Saud University, Riyadh, Saudi Arabia, for its support.

\section{Compliance with ethical standards}

Conflict of interest $\mathrm{MH}$ has received research grant through institution from Amgen, Radius, and Teva, lecture fees from Radius, and paid advisory board from UCB. JYR has received research grant and/or consulting fees from Servier, Novartis, Negma, Lilly, Wyeth, Amgen, GlaxoSmithKline, Roche, Merckle, Nycomed-Takeda, NPS, IBSA Genevrier, Theramex, UCB, Asahi Kasei, Endocyte, Merck Sharp and Dohme, Rottapharm, Teijin, Teva, Analis, NovoNordisk, Ebewee Pharma, Zodiac, Danone, Will Pharma, Meda, Bristol Myers Squibb, Pfizer, Organon, Therabel, Boehringer, Chiltern, and Galapagos. KGS has received research funding from Amgen, Mereo, and Radius and has consulted for Amgen, Lilly, Radius, and Roche; he is on the National Osteoporosis Foundation Board of Trustees. DTG has received 
consulting fees from Amgen, Eli Lilly, and Radius. EML has received institutional grant/research support from Amgen, PFEnex, and Mereo; he has served on scientific advisory boards for Amgen, Radius, Shire, Alexion, Ultragenyx, and Sandoz; he serves on the speakers' bureau for Shire, Alexion, and Radius; he is a board member of the National Osteoporosis Foundation, International Society for Clinical Densitometry, and Osteoporosis Foundation of New Mexico. JDA is an investigative site for clinical trials for Amgen, consultant and speaker for Amgen. OB received research grants from Biophytis, IBSA, Meda, Servier, and SMB and consulting fees from Biophytis, IBSA, MEDA, Servier, SMB, and TRB Chemedica. MC has received honoraria for speaking engagements with AMGEN and Eli Lilly and has served on the scientific advisory board of MSD. CC reports personal fees from Alliance for Better Bone Health, Amgen, Eli Lilly, GSK, Medtronic, Merck, Novartis, Pfizer, Roche, Servier, Takeda, and UCB. NCH has received consultancy, lecture fees, and honoraria from Alliance for Better Bone Health, Amgen, Merck Sharp \& Dohme, Eli Lilly, Servier, Shire, UCB, Consilient Healthcare, and Internis Pharma. TAE has been scientific Advisory Board for AGnovos, consultant for Terumo, stock owner for PolyPid, and grant recipient from Orthofix. JAK reports grants from Amgen, grants from Lilly, grants from Radius Health, grants from $\mathrm{UCB}$, other from Meda, outside the submitted work; and he is the principal architect of FRAX but derives no financial benefit. DLK has received research grants, advisory honoraria, and/or speaker honoraria from Amgen, Eli Lilly, Astrazenica, and Pfizer. ODM has been consultant for Amgen, Lilly, Pfizer, UCB, American Health Foundation (AHF), Gilead. RR has received consulting or lecture fees from Radius Health, CNIEL, Effryx, Theramex, Danone, and Nestlé. LS has received a National Health and Medical Research Council (NHMRC) grant (1127827) and a NHMRC Early Career Fellowship (1139826) for his research time. SS has received grant support from Amgen, Radius, and Lilly; he has received consulting fees from Amgen and Radius; he has served on scientific advisory boards for Lilly and Amgen; and he has served on speakers bureaus for Amgen, Lilly, and Radius. ANT, SVK, PH, FJ, DP, and NAD have no conflicts of interest to report.

Open Access This article is distributed under the terms of the Creative Commons Attribution-NonCommercial 4.0 International License (http:// creativecommons.org/licenses/by-nc/4.0/), which permits any noncommercial use, distribution, and reproduction in any medium, provided you give appropriate credit to the original author(s) and the source, provide a link to the Creative Commons license, and indicate if changes were made.

\section{References}

1. Hiligsmann M, Kanis JA, Compston J, Cooper C, Flamion B, Bergmann P, Body JJ, Boonen S, Bruyere O, Devogelaer JP, Goemaere S, Kaufman JM, Rozenberg S, Reginster JY (2013) Health technology assessment in osteoporosis. Calcif Tissue Int 93(1):1-14

2. Bracco A, Krol M (2013) Economic evaluations in European reimbursement submission guidelines: current status and comparisons. Expert Rev Pharmacoecon Outcomes Res 13(5):579-595

3. Hiligsmann M, Evers SM, Ben Sedrine W, Kanis JA, Ramaekers B, Reginster JY, Silverman S, Wyers CE, Boonen A (2015) A systematic review of cost-effectiveness analyses of drugs for postmenopausal osteoporosis. PharmacoEconomics 33(8):205-224

4. Brandao CM, Machado GP, Acurcio Fde A (2012) Pharmacoeconomic analysis of strategies to treat postmenopausal osteoporosis: a systematic review. Rev Bras Reumatol 52(6):924-937
5. Hiligsmann M, Reginster JY (2011) Cost effectiveness of denosumab compared with oral bisphosphonates in the treatment of post-menopausal osteoporotic women in Belgium. PharmacoEconomics 29(10):895-911

6. Kanis JA, McCloskey EV, Johansson H, Cooper C, Rizzoli R, Reginster JY, Scientific Advisory Board of the European Society for Clinical and Economic Aspects of Osteoporosis and Osteoarthritis (ESCEO) and the Committee of Scientific Advisors of the International Osteoporosis Foundation [68] (2013) European guidance for the diagnosis and management of osteoporosis in postmenopausal women. Osteoporos Int 24(1):23-57

7. Kanis JA, McCloskey EV, Johansson H, Strom O, Borgstrom F, Oden A, National Osteoporosis Guideline Group (2008) Case finding for the management of osteoporosis with FRAX-assessment and intervention thresholds for the UK. Osteoporos Int 19(10): $1395-1408$

8. Tosteson AN, Melton LJ 3rd, Dawson-Hughes B, Baim S, Favus MJ, Khosla S, Lindsay RL, National Osteoporosis Foundation Guide Committee (2008) Cost-effective osteoporosis treatment thresholds: the United States perspective. Osteoporos Int 19(4): 437-447

9. Lippuner K, Johansson H, Borgstrom F, Kanis JA, Rizzoli R (2012) Cost-effective intervention thresholds against osteoporotic fractures based on FRAX (R) in Switzerland. Osteoporos Int 23(11):2579-2589

10. Hiligsmann M, Gathon HJ, Bruyere O, Ethgen O, Rabenda V, Reginster JY (2010) Cost-effectiveness of osteoporosis screening followed by treatment: the impact of medication adherence. Value Health 13(4):394-401

11. Turner DA, Khioe RFS, Shepstone L, Lenaghan E, Cooper C, Gittoes N, Harvey NC, Holland R, Howe A, McCloskey E, O'Neill TW, Torgerson D, Fordham R, the SCOOP Study Team (2018) The cost-effectiveness of screening in the community to reduce osteoporotic fractures in older women in the UK: economic evaluation of the SCOOP study. J Bone Miner Res 33(5):845-851

12. Wu CH, Kao IJ, Hung WC, Lin SC, Liu HC, Hsieh MH, Bagga S, Achra M, Cheng TT, Yang RS (2018) Economic impact and costeffectiveness of fracture liaison services: a systematic review of the literature. Osteoporos Int 29(6):1227-1242

13. Caro JJ, Briggs AH, Siebert U, Kuntz KM, ISPOR-SMDM Modeling Good Research Practices Task Force (2012) Modeling good research practices-overview: a report of the ISPOR-SMDM Modeling Good Research Practices Task Force-1. Value Health 15(6):796-803

14. Husereau D, Drummond M, Petrou S, Carswell C, Moher D, Greenberg D, Augustovski F, Briggs AH, Mauskopf J, Loder E (2013) Consolidated Health Economic Evaluation Reporting Standards (CHEERS) statement. PharmacoEconomics 31(5): 361-367

15. Sanders GD, Neumann PJ, Basu A, Brock DW, Feeny D, Krahn M, Kuntz KM, Meltzer DO, Owens DK, Prosser LA, Salomon JA, Sculpher MJ, Trikalinos TA, Russell LB, Siegel JE, Ganiats TG (2016) Recommendations for conduct, methodological practices, and reporting of cost-effectiveness analyses: second panel on cost-effectiveness in health and medicine. JAMA 316(10):1093-1103

16. Maetzel A, Tugwell P, Boers M, Guillemin F, Coyle D, Drummond M, Wong JB, Gabriel SE, OMERACT 6 Economics Research Group (2003) Economic evaluation of programs or interventions in the management of rheumatoid arthritis: defining a consensusbased reference case. J Rheumatol 30(4):891-896

17. Hiligsmann M, Cooper C, Guillemin F, Hochberg MC, Tugwell P, Arden N, Berenbaum F, Boers M, Boonen A, Branco JC, MariaLuisa B, Bruyère O, Gasparik A, Kanis JA, Kvien TK, MartelPelletier J, Pelletier JP, Pinedo-Villanueva R, Pinto D, ReiterNiesert S, Rizzoli R, Rovati LC, Severens JL, Silverman S, Reginster JY (2014) A reference case for economic evaluations in 
osteoarthritis: an expert consensus article from the European Society for Clinical and Economic Aspects of Osteoporosis and Osteoarthritis (ESCEO). Semin Arthritis Rheum 44(8):271-282

18. Drummond M, Maetzel A, Gabriel S, March L (2003) Towards a reference case for use in future economic evaluations of interventions in osteoarthritis. J Rheumatol 68:26-30

19. Dere W, Avouac B, Boers M, Buxton M, Christiansen C, Dawson A, Gennari C, Guillemin F, Lawaetz H, Ornskov F et al (1998) Recommendations for the health economics analysis to be performed with a drug to be registered in prevention or treatment of osteoporosis. Calcif Tissue Int 63(2):93-97

20. Kahn R (2004) Guidelines for computer modeling of diabetes and its complications. Diabetes Care 27(9):2262-2265

21. Miller PD, Hattersley G, Riis BJ, Williams GC, Lau E, Russo LA, Alexandersen P, Zerbini CA, Hu MY, Harris AG et al (2016) Effect of abaloparatide vs placebo on new vertebral fractures in postmenopausal women with osteoporosis: a randomized clinical trial. JAMA 316(7):722-733

22. Saag KG, Petersen J, Brandi ML, Karaplis AC, Lorentzon M, Thomas T, Maddox J, Fan M, Meisner PD, Grauer A (2017) Romosozumab or alendronate for fracture prevention in women with osteoporosis. N Engl J Med 377(15):1417-1427

23. Cosman F, Miller PD, Williams GC, Hattersley G, Hu MY, Valter I, Fitzpatrick LA, Riis BJ, Christiansen C, Bilezikian JP, Black D (2017) Eighteen months of treatment with subcutaneous abaloparatide followed by 6 months of treatment with alendronate in postmenopausal women with osteoporosis: results of the ACTIVExtend trial. Mayo Clin Proc 92(2):200-210

24. Cosman F, Nieves JW, Dempster DW (2017) Treatment sequence matters: anabolic and antiresorptive therapy for osteoporosis. $\mathrm{J}$ Bone Miner Res 32(2):198-202

25. Tsourdi E, Langdahl B, Cohen-Solal M, Aubry-Rozier B, Eriksen EF, Guanabens N, Obermayer-Pietsch B, Ralston SH, Eastell R, Zillikens MC (2017) Discontinuation of Denosumab therapy for osteoporosis: a systematic review and position statement by ECTS. Bone 105:11-17

26. Johansson H, Siggeirsdottir K, Harvey NC, Oden A, Gudnason V, McCloskey E, Sigurdsson G, Kanis JA (2017) Imminent risk of fracture after fracture. Osteoporos Int 28(8):775-780

27. Kanis JA, Johnell O, Oden A, Johansson H, McCloskey E (2008) FRAX and the assessment of fracture probability in men and women from the UK. Osteoporos Int 19(4):385-397

28. Zethraeus N, Borgstrom F, Strom O, Kanis JA, Jonsson B (2007) Cost-effectiveness of the treatment and prevention of osteoporosisa review of the literature and a reference model. Osteoporos Int 18(1):9-23

29. Hiligsmann M, Ethgen O, Bruyere O, Richy F, Gathon HJ, Reginster JY (2009) Development and validation of a Markov microsimulation model for the economic evaluation of treatments in osteoporosis. Value Health 12(5):687-696

30. Silverman S, Agodoa I, Kruse M, Parthan A, Orwoll E (2015) Denosumab for elderly men with osteoporosis: a costeffectiveness analysis from the US payer perspective. J Osteoporos 2015:627631

31. Liu H, Michaud K, Nayak S, Karpf DB, Owens DK, Garber AM (2006) The cost-effectiveness of therapy with teriparatide and alendronate in women with severe osteoporosis. Arch Intern Med 166(11):1209-1217

32. Technical appendix of Liu, $\mathrm{H}$ et al (2006) The cost-effectiveness of therapy with teriparatide and alendronate in women with severe osteoporosis. Arch Intern Med 166(11):1209-1217

33. Institute for Clinical and Economic Review (2017) Anabolic therapies for osteoporosis in postmenopausal women: effectiveness and value. Available from: https://icer-review.org/wp-content/uploads/ 2016/11/CTAF Osteoporosis Evidence Report 061617.pdf. Access on Feb 2018
34. National Institute for Care and Health Excellence (2018) Bisphosphonate for treating osteoporosis. United Kingdom. Available from https://www.nice.org.uk/guidance/ta464. Access on Feb 2018

35. Harrison MJ, Bansback NJ, Marra CA, Drummond M, Tugwell PS, Boonen A (2011) Valuing health for clinical and economic decisions: directions relevant for rheumatologists. J Rheumatol 38(8): $1770-1775$

36. Pettitt D, Raza S, Naughton B, Roscoe A, Ramakrishnan A, Ali A, Davies B, Dopson S, Hollander G, Smith J et al (2016) The limitations of QALY: a literature review. Journal of Stem Cell Research \& Therapy 6(4). https://doi.org/10.4172/2157-7633.1000334

37. Sculpher MJ, Claxton K, Drummond M, McCabe C (2006) Whither trial-based economic evaluation for health care decision making? Health Econ 15(7):677-687

38. Brennan A, Akehurst R (2000) Modelling in health economic evaluation. What is its place? What is its value? PharmacoEconomics 17(5):445-459

39. Kanis JA, Oden A, Johnell O, Jonsson B, de Laet C, Dawson A (2001) The burden of osteoporotic fractures: a method for setting intervention thresholds. Osteoporos Int 12(5):417-427

40. Camacho PM, Petak SM, Binkley N, Clarke BL, Harris ST, Hurley DL, Kleerekoper M, Lewiecki EM, Miller PD, Narula HS, PessahPollack R, Tangpricha V, Wimalawansa SJ, Watts NB, American Association of Clinical Endocrinologists and American College of Endocrinology (2016) Clinical practice guidelines for the diagnosis and treatment of postmenopausal osteoporosis. Endocr Pract 22(Suppl 4):1-42

41. Kanis JA, Johnell O, Oden A, Jonsson B, De Laet C, Dawson A (2000) Risk of hip fracture according to the World Health Organization criteria for osteopenia and osteoporosis. Bone 27(5): $585-590$

42. Klotzbuecher CM, Ross PD, Landsman PB, Abbott TA, Berger M (2000) Patients with prior fractures have an increased risk of future fractures: a summary of the literature and statistical synthesis. J Bone Miner Res 15(4):721-739

43. Haentjens P, Magaziner J, Colon-Emeric CS, Vanderschueren D, Milisen K, Velkeniers B, Boonen S (2010) Meta-analysis: excess mortality after hip fracture among older women and men. Ann Intern Med 152(6):380-390

44. Kanis JA, Oden A, Johnell O, De Laet C, Jonsson B (2004) Excess mortality after hospitalisation for vertebral fracture. Osteoporos Int 15(2):108-112

45. Kanis JA, Oden A, Johnell O, De Laet C, Jonsson B, Oglesby AK (2003) The components of excess mortality after hip fracture. Bone 32(5):468-473

46. Si L, Winzenberg TM, de Graaff B, Palmer AJ (2014) A systematic review and meta-analysis of utility-based quality of life for osteoporosis-related conditions. Osteoporos Int 25(8):1987-1997

47. Svedbom A, Borgstrom F, Hernlund E, Strom O, Alekna V, Bianchi ML, Clark P, Curiel MD, Dimai HP, Jurisson M et al (2018) Quality of life after hip, vertebral, and distal forearm fragility fractures measured using the EQ-5D-3L, EQ-VAS, and time-trade-off: results from the ICUROS. Qual Life Res 27(8):707-716

48. Kanis JA, Johansson H, Odén A, Harvey NC, Gudnason V, Sanders K, Sigurdsson G, Siggeirsdottir K, Borgström F, McCloskey EV (2018) Characteristics of recurrent fractures. Osteoporos Int 2018 Aug;29(8):1747-1757

49. Borgstrom F, Lekander I, Ivergard M, Strom O, Svedbom A, Alekna V, Bianchi ML, Clark P, Curiel MD, Dimai HP et al (2013) The International Costs and Utilities Related to Osteoporotic Fractures Study (ICUROS)-quality of life during the first 4 months after fracture. Osteoporos Int 24(8):811-823

50. Kanis JA, Cooper C, Rizzoli R, Reginster JY (2018) Review of the guideline of the American College of Physicians on the treatment of osteoporosis. Osteoporos Int 29:1505-1510 
51. Reginster JY, Rizzoli R, Kanis JA, Cooper C (2017) Treatment of low bone density or osteoporosis to prevent fractures in men and women. Ann Intern Med 167(12):902-903

52. Jonsson B, Kanis J, Dawson A, Oden A, Johnell O (1999) Effect and offset of effect of treatments for hip fracture on health outcomes. Osteoporos Int 10(8):193-199

53. Strom O, Landfeldt E, Garellick G (2015) Residual effect after oral bisphosphonate treatment and healthy adherer effects-the Swedish adherence register analysis [69]. Osteoporos Int 26(1):315-325

54. Lindsay R, Scheele WH, Neer R, Pohl G, Adami S, Mautalen C, Reginster JY, Stepan JJ, Myers SL, Mitlak BH (2004) Sustained vertebral fracture risk reduction after withdrawal of teriparatide in postmenopausal women with osteoporosis. Arch Intern Med 164(18):2024-2030

55. Prince R, Sipos A, Hossain A, Syversen U, Ish-Shalom S, Marcinowska E, Halse J, Lindsay R, Dalsky GP, Mitlak BH (2005) Sustained nonvertebral fragility fracture risk reduction after discontinuation of teriparatide treatment. J Bone Miner Res 20(9): $1507-1513$

56. McClung MR, Wagman RB, Miller PD, Wang A, Lewiecki EM (2017) Observations following discontinuation of long-term denosumab therapy. Osteoporos Int 28(5):1723-1732

57. Hiligsmann M, Rabenda V, Gathon HJ, Ethgen O, Reginster JY (2010) Potential clinical and economic impact of nonadherence with osteoporosis medications. Calcif Tissue Int 86(8):202-210

58. Hiligsmann M, Boonen A, Rabenda V, Reginster JY (2012) The importance of integrating medication adherence into pharmacoeconomic analyses: the example of osteoporosis. Expert Rev Pharmacoecon Outcomes Res 12(2):159-166

59. Kanis JA, Cooper C, Hiligsmann M, Rabenda V, Reginster JY, Rizzoli R (2011) Partial adherence: a new perspective on health economic assessment in osteoporosis. Osteoporos Int 22(10): $2565-2573$
60. Strom O, Borgstrom F, Kanis J, Jonsson B (2009) Incorporating adherence into health economic modelling of osteoporosis. Osteoporos Int 20(1):23-34

61. Eddy DM, Hollingworth W, Caro JJ, Tsevat J, McDonald KM, Wong JB, ISPOR-SMDM Modeling Good Research Practices Task Force (2012) Model transparency and validation: a report of the ISPOR-SMDM Modeling Good Research Practices Task Force-7. Value Health 15(6):843-850

62. Briggs A, Claxton K, Sculpher M (2006) Decision modelling for health economic evaluation. Oxford University Press, Oxford

63. Kanis JA, Harvey NC, Cooper C, Johansson H, Oden A, McCloskey EV, Advisory Board of the National Osteoporosis Guideline Group (2016) A systematic review of intervention thresholds based on FRAX: a report prepared for the National Osteoporosis Guideline Group and the International Osteoporosis Foundation. Arch Osteoporos 11(1):25

64. Kanis JA, Johnell O, Oden A, Sernbo I, Redlund-Johnell I, Dawson A, De Laet C, Jonsson B (2000) Long-term risk of osteoporotic fracture in Malmo. Osteoporos Int 11(8):669-674

65. Oden A, Dawson A, Dere W, Johnell O, Jonsson B, Kanis JA (1998) Lifetime risk of hip fractures is underestimated. Osteoporos Int 8(6):599-603

66. Tran T, Bliuc D, van Geel T, Adachi JD, Berger C, van den Bergh J, Eisman JA, Geusens P, Goltzman D, Hanley DA, Josse RG, Kaiser SM, Kovacs CS, Langsetmo L, Prior JC, Nguyen TV, Center JR (2017) Population-wide impact of non-hip non-vertebral fractures on mortality. J Bone Miner Res 32(9):1802-1810

67. Drost RMWA, van der Putten IM, Ruwaard D, Evers SMAA, Paulus ATG (2017) Conceptualizations of the societal perspective within economic evaluations: a systematic review. Int J Technol Assess Health Care 33(2):251-260

\section{Affiliations}

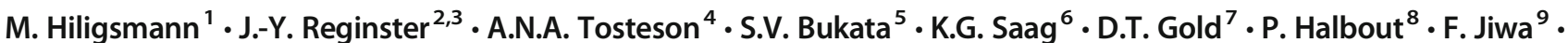
E.M. Lewiecki ${ }^{10}$-D. Pinto ${ }^{11,12} \cdot$ J.D. Adachi ${ }^{13} \cdot$ N. Al-Daghri ${ }^{3} \cdot$ O. Bruyère ${ }^{2} \cdot$ M. Chandran $^{14} \cdot$ C. Cooper $^{15,16}$. $^{17}$.

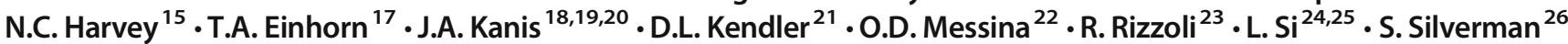

1 Department of Health Services Research, CAPHRI Care and Public Health Research Institute, Maastricht University, Maastricht, The Netherlands

2 Department of Public Health, Epidemiology and Health Economics, University of Liège, Liège, Belgium

3 Chair for Biomarkers of Chronic Diseases, Biochemistry Department, College of Science, King Saud University, Riyadh, Kingdom of Saudi Arabia

4 The Dartmouth Institute for Health Policy and Clinical Practice, Geisel School of Medicine at Dartmouth, Lebanon, NH, USA

5 UCLA Orthopaedic Center, Santa Monica, CA, USA

6 Division of Clinical Immunology and Rheumatology, Department of Medicine, University of Alabama at Birmingham, Birmingham, AL, USA

7 Department of Psychiatry and Behavioral Sciences, Duke University Medical Center, Durham, NC, USA
8 International Osteoporosis Foundation, Nyon, Switzerland

9 Patients Societies at the International Osteoporosis Foundation, Osteoporosis Canada, Toronto, Canada

10 New Mexico Clinical Research \& Osteoporosis Center, Albuquerque, NM, USA

11 Department of Physical Therapy, Marquette University, Milwaukee, USA

12 Center for Healthcare Studies, Feinberg School of Medicine, Northwestern University, Chicago, USA

13 Department of Medicine, McMaster University, Hamilton, ON, Canada

14 Osteoporosis and Bone Metabolism Unit, Department of Endocrinology, Singapore General Hospital, Singapore, Singapore

15 MRC Lifecourse Epidemiology Unit, University of Southampton, Southampton, UK 
16 UKNIHR Oxford Biomedical Research Centre, University of Oxford, Oxford, UK

17 New York University Langone Health, New York, USA

18 Centre for Metabolic Bone Diseases, University of Sheffield, Sheffield, UK

19 University of Sheffield Medical School, Sheffield, UK

20 Mary McKillop Health Institute, Australian Catholic University, Melbourne, Australia

21 University of British Columbia, Vancouver, Canada
22 Cosme Argerich Hospital and IRO medical research centre, Buenos Aires, Argentina

23 Service of Bone Diseases, Faculty of Medicine, Geneva University Hospitals, Geneva, Switzerland

24 The George Institute for Global Health, University of New South Wales, Kensington, NH, Australia

25 Centre for the Health Economy, Macquarie University, Sydney, NSW, Australia

26 Cedars-Sinai Medical Center, UCLA School of Medicine and the OMC Clinical Research Center, Los Angeles, CA, USA 